\title{
Redistribution and Effect of Various Elements on the Morphology of Primary Graphite in Cast Iron
}

\author{
J. Lacaze, ${ }^{1}$ N. Valle, ${ }^{2}$ K. Theuwissen, ${ }^{1}$ J. Sertucha, ${ }^{3}$ B. El Adib, ${ }^{2}$ and L. Laffont ${ }^{1}$ \\ ${ }^{1}$ CIRIMAT, Université de Toulouse, ENSIACET, 31432 Toulouse Cedex 4, France \\ ${ }^{2}$ Department "Science and Analysis of Materials" (SAM), Centre de Recherche Public-Gabriel Lippmann 41 rue du Brill, \\ 4422 Belvaux, Luxembourg \\ ${ }^{3}$ Engineering and Foundry Processes Department, AZTERLAN, Aliendalde Auzunea 6, Bizkaia, 48200 Durango, Spain
}

Correspondence should be addressed to J. Lacaze; jacques.lacaze@ensiacet.fr

Received 1 February 2013; Accepted 24 May 2013

Academic Editor: Steven Suib

Copyright (C) 2013 J. Lacaze et al. This is an open access article distributed under the Creative Commons Attribution License, which permits unrestricted use, distribution, and reproduction in any medium, provided the original work is properly cited.

It has been shown repeatedly that many elements present as traces or at low level can affect graphite shape in cast irons. As part of a long term project aimed at clarifying the growth and the alteration of spheroidal graphite, a study on the effect of a few elements $(\mathrm{Cu}$, $\mathrm{Sn}, \mathrm{Sb}$, and $\mathrm{Ti}$ ) on primary graphite growth was undertaken and analysed with reference to an alloy without any such additions. This work was performed by remelting alloys in graphite crucibles thus saturating the melt in carbon and enabling primary graphite to grow by controlled cooling of the melt above the eutectic temperature. Primary graphite growth in the reference alloy was observed to be lamellar, while the added elements were found to affect bulk graphite and to modify its outer shape, with Sb leading eventually to rounded agglomerates together with wavy lamellae. Secondary ion mass spectrometry was used to analyze the distribution of elements, and no build-up of trace elements at the graphite surface could be observed. Instead, it is established that the perturbation of bulk graphite is associated with inhomogeneous distribution of metallic elements inside graphite precipitates.

\section{Introduction}

Graphite in cast irons can adopt various shapes partly depending not only on cooling rate but also on the presence of additives or of trace elements. Without appropriate preparation, graphite precipitates as lamellae (GL), and this has been in part related to the presence of oxygen and sulfur dissolved in cast iron melts. These latter elements may be withdrawn from the melt by adding 0.025 to $0.050 \mathrm{wt} . \% \mathrm{Mg}$ (or Mg associated with $\mathrm{Ce}$ ) which ensure in most cases that graphite precipitates as spheroids (SG) while intermediate amounts of $\mathrm{Mg}$ (0.009-0.018 wt.\%) lead to compacted graphite (CG). Further, many elements other than $\mathrm{O}$ and $\mathrm{S}$ when present even as traces lead to degenerate forms of graphite, that is, neither lamellar nor spheroidal. Values of their maximum permissible content for obtaining SG irons have been reviewed by Lux [1]. Sorting of trace elements has been proposed [2,3] for describing their effect on spheroidal graphite growth:

(i) reducing the effectiveness of $\mathrm{Mg}$, for example, $\mathrm{O}, \mathrm{S}$, $\mathrm{Se}, \mathrm{Te}$, and $\mathrm{Ti}$; (ii) altering graphite growth, for example, $\mathrm{Al}, \mathrm{As}, \mathrm{Bi}, \mathrm{Cd}$, $\mathrm{Cu}, \mathrm{Pb}, \mathrm{Sb}$, and $\mathrm{Sn}$

(iii) promoting degenerate graphite in heavy-section castings, for example, $\mathrm{Ce}$ and $\mathrm{Ca}$.

Interest has been put for long on graphite chemistry as it may be expected that modifiers get incorporated into the graphite lattice [1]. For such a purpose, the most usual means as electron probe or energy dispersive analyzers often have too poor detection limits. Francis [4] used chemical analysis of extracted graphite and reported that many elements could be detected in graphite. Auger electron spectroscopy (AES) has also been used, but generally it only gives information on the interface and not on the bulk of the phases. Although proton emission has been successfully used $[5,6]$, the most potential means thanks to its high sensitivity appeared to be secondary ion mass spectrometry (SIMS) that has already been used by a few authors [7-10].

In an attempt to enlighten the effect of some additives and trace elements on graphite growth, experiments have been 
TABLE 1: Composition of the investigated alloys (wt.\%). Elements added specifically for this study are in bold.

\begin{tabular}{lccccccccccccc}
\hline Alloy & $\mathrm{C}$ & $\mathrm{Si}$ & $\mathrm{Mn}$ & $\mathrm{P}$ & $\mathrm{S}$ & $\mathrm{Mg}$ & $\mathrm{Cu}$ & $\mathrm{Ti}$ & $\mathrm{Al}$ & $\mathrm{N}$ & $\mathrm{Ni}$ & $\mathrm{Other}$ \\
\hline 10F2 & 3.64 & 2.05 & 0.11 & 0.033 & 0.015 & 0.037 & $\mathbf{0 . 0 4}$ & - & - & 0.0050 & 0.03 & $0.003 \mathrm{Bi}$ \\
8P1-Cu & 3.73 & 2.42 & 0.45 & 0.035 & 0.015 & 0.033 & $\mathbf{0 . 9 5}$ & - & 0.010 & 0.0041 & 0.02 & $\mathbf{0 . 0 0 5} \mathbf{S n}$ \\
8P3-Sn & 3.49 & 2.60 & 0.40 & 0.035 & 0.015 & 0.033 & $\mathbf{0 . 8 6}$ & - & 0.006 & 0.0047 & 0.02 & $\mathbf{0 . 0 2 4} \mathbf{S n}$ \\
9P3-Sb & 3.52 & 2.24 & 0.82 & 0.038 & 0.012 & 0.035 & $\mathbf{1 . 0 8}$ & $\mathbf{0 . 0 2 2}$ & 0.011 & 0.0038 & 0.04 & $\mathbf{0 . 0 0 5} \mathbf{S b}$ \\
12P3-Ti & 3.65 & 1.98 & 0.37 & 0.026 & 0.013 & 0.039 & $\mathbf{0 . 8 5}$ & $\mathbf{0 . 3 6}$ & $<0.010$ & 0.0033 & 0.07 & - \\
\hline
\end{tabular}

carried out with a standard cast iron and four grades with about 1 wt.\% $\mathrm{Cu}$ and additions of Sb, Sn, or Ti. These alloys have been remelted and resolidified in graphite crucibles so as to saturate the melt in carbon, much in line with the work by Geilenberg et al. [11, 12]. Primary graphite precipitates have been characterized by optical and scanning electron microscopy and analyzed with SIMS. This work provides also a detailed comparison of the present results to the literature information.

\section{Experimental Details}

All melts were prepared as previously described $[13,14]$. Alloying of the melts was performed by extra additions of $\mathrm{Cu}$, FeMn, FeTi, Sn, and/or Sb to a standard cast iron that will be called reference alloy in the following. The alloys were cast in standard keel-blocks representative of small-section mould castings and generally used for materials testing as described elsewhere [15]. The final composition of the alloys is listed in Table 1. A few other additional elements were found in some of the melts: B (0.0059 wt.\%) in the reference alloy (10F2), Cr (0.03 wt.\%) in 8P1-Cu and 8P3-Sn, $\mathrm{Zr}$ (at most 0.005 wt.\%) in $9 \mathrm{P} 3-\mathrm{Sb}$, and Mo (0.01 wt.\%) in all four alloys with specific additions.

These alloys were remelted in graphite crucibles (crucibles ALPHA AR6247 designed for chemical analysis of oxygen and nitrogen) by heating to $1300^{\circ} \mathrm{C}$ and held at that temperature for $10 \mathrm{~min}$. This led to volatilization of the magnesium added for spheroidization and to carbon saturation of the liquid (see Figure 1). The samples were then cooled to $1180^{\circ} \mathrm{C}$ in about $10 \mathrm{~min}$ at a cooling rate of $25^{\circ} \mathrm{C} / \mathrm{min}$ and maintained at that temperature for $20 \mathrm{~min}$. During the stages of cooling from $1300^{\circ} \mathrm{C}$ and holding at $1180^{\circ} \mathrm{C}$, primary graphite precipitates were expected to nucleate and grow along the crucible walls. Finally, the crucibles were extracted from the furnace and quenched with air blowing which led to rapid solidification of the remaining melt at a rate of about $250^{\circ} \mathrm{C} / \mathrm{min}$. The samples were then vertically cut and prepared for metallographic observation, including optical and scanning electron (SEM) microscopy.

SIMS analyses were performed on a modified CAMECA IMS-6f equipped with a gallium liquid metal ion gun. Although the $\mathrm{Ga}^{+}$source is able to reach a good lateral resolution better than $100 \mathrm{~nm}$ in some cases [16], its use is limited due to low ion yield. In order to achieve a sensitivity enhancement under $\mathrm{Ga}^{+}$bombardment, the measurements were assisted with oxygen flooding $\left(P=10^{-6} \mathrm{mbar}\right)$ as described by Frache et al. [17]. In such conditions, the lateral resolution of the SIMS probe remains better than $1 \mu \mathrm{m}$.

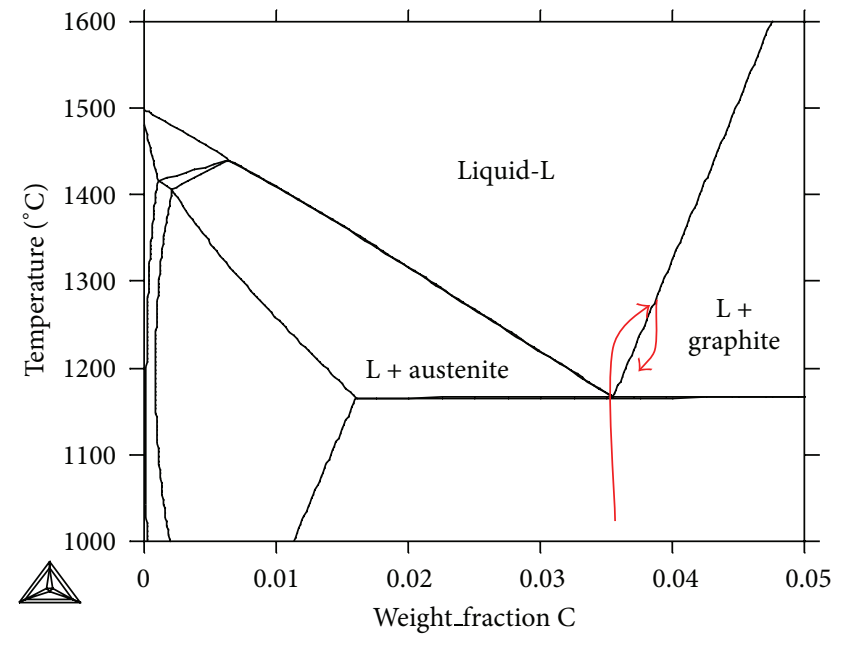

Figure 1: Fe-C isopleth section of the Fe-C-Si diagram at 2.5 wt.\% $\mathrm{Si}$. The arrows indicate the temperature-composition path followed by the material upon melting, holding at $1300^{\circ} \mathrm{C}$, and then cooling to and holding at $1180^{\circ} \mathrm{C}$.

$\mathrm{A} \mathrm{Ga}^{+}$beam $(25.5 \mathrm{keV})$ was focused down to $500 \mathrm{~nm}$ in diameter with an intensity of $150 \mathrm{pA}$ and was scanned across an area of $(50 \times 50) \mu \mathrm{m}^{2}$. Elements were analyzed as positive ions. The counting times were $20 \mathrm{~s}$ for ${ }^{12} \mathrm{C},{ }^{24} \mathrm{Mg}$ and ${ }^{25} \mathrm{Mg}$, the three silicon isotopes, ${ }^{52} \mathrm{Cr},{ }^{54} \mathrm{Fe}$ and ${ }^{56} \mathrm{Fe}$, and ${ }^{55} \mathrm{Mn}$ and $40 \mathrm{~s}$ for ${ }^{48} \mathrm{Ti},{ }^{63} \mathrm{Cu}$ and ${ }^{64} \mathrm{Cu},{ }^{119} \mathrm{Sn},{ }^{120} \mathrm{Sn}$, and ${ }^{121} \mathrm{Sb}$. The definition of the images was $256 \times 256$ pixels. The different images were acquired successively, from the lowest (12 for carbon) to the highest (121 for Sb) atomic mass giving the plane 1 for each element studied. Then new successive series of acquisition were performed, giving planes 2, 3,..,8. For elements present as traces (for instance Sb, and $\mathrm{Sn}$ ), the signal obtained for all planes (from plane 1 to 8 ) was accumulated in order to increase the statistics of the measurements. For all the other elements present in higher quantities, the signal from only one plane was high enough to be meaningful. The detection limit was estimated to a few tens of ppm for every element.

SIMS images were complemented with records of the variation of the secondary ion intensities across graphite lamellae (line scans). This was performed by integrating the intensities measured from one or several planes (for Sn and $\mathrm{Sb})$ over 10 pixels in width, that is, about $2 \mu \mathrm{m}$ for the conditions used in the present study.

Finally, SIMS quantification of trace element concentrations in the iron-rich matrix was based on relative sensitivity 


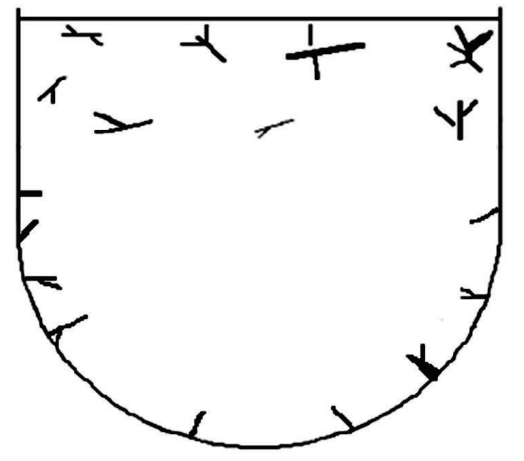

(a)

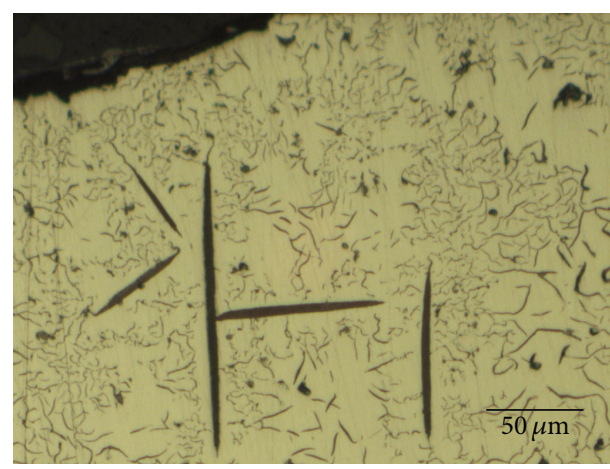

(b)

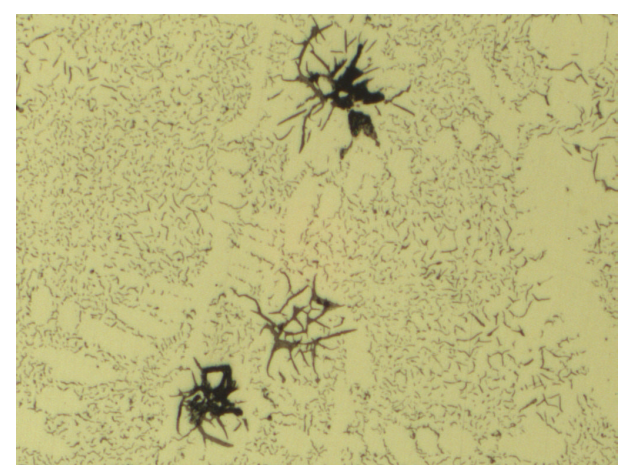

(c)

FIGURE 2: Schematic section of the samples showing the location of primary graphite lamellae (a) and optical micrograph at the top (b) and middle (c) of the vertical section of the reference 10F2 sample. The scale is the same for both micrographs.

factors (RSF) derived from four standard iron-base alloys with certified compositions. The $\mathrm{RSF}_{\mathrm{X}}$ factor for element $\mathrm{X}$ is given by $\mathrm{RSF}_{\mathrm{X}}=C_{\mathrm{x}} \times\left(I_{\mathrm{Fe}} / I_{\mathrm{X}}\right)$ where $C_{\mathrm{X}}$ is the concentration of trace species $\mathrm{X}, I_{\mathrm{X}}$ and $I_{\mathrm{Fe}}$ are the secondary ion intensities measured, respectively, for element $\mathrm{X}$ and for iron used as reference element. The RSFs were derived from the slope of the straight line $I_{\mathrm{X}} / I_{\mathrm{Fe}}=f\left(C_{\mathrm{X}}\right)$ for $\mathrm{Al}, \mathrm{Cu}, \mathrm{Cr}, \mathrm{Mn}, \mathrm{Si}, \mathrm{Sb}, \mathrm{Sn}$, and Ti. Because the standards do not contain magnesium, the determination of $\mathrm{RSF}_{\mathrm{Mg}}$ was not possible. Nevertheless, the $\mathrm{Mg}$ content was estimated by assuming that $\mathrm{RSF}_{\mathrm{Mg}}$ was equal to $\operatorname{RSF}_{\mathrm{Ti}}[18]$.

\section{Results}

As schematically illustrated in Figure 2(a), the vertical section of every sample showed some large graphite precipitates attached along the crucible walls, but most of these precipitates accumulated close to the top surface of the samples. As an example, Figure 2(b) presents part of the top surface of the reference alloy. In the remaining volume of the samples, much smaller primary precipitates of graphite were observed and most of the material is essentially composed of austenite dendrites and eutectic with undercooled graphite; see Figure 2(c). The large precipitates of graphite may without doubt be associated to primary deposition of this phase, suggesting that after nucleation and growth on the crucible walls they detached and floated due to the density difference between graphite and liquid iron. The finer solidification structures seen in the remaining of the materials have certainly been formed after the crucible was withdrawn out of the furnace. Accordingly, emphasis will be put in the following on the large graphite precipitates.

Figure 3 shows a characteristic optical micrograph of primary graphite precipitates for each of the four alloys with specific additions. Comparing to Figure 2(b), the effect of $\mathrm{Cu}$ seems limited to a very slight thickening of the lamellae while this phenomenon appeared much more pronounced after Sn addition. The most impressive effect relates to the alloy with $\mathrm{Sb}$ that led to a few thick lamellae but mainly to rounded agglomerates. Finally, Ti had apparently a significantly different effect in that it greatly reduced graphite nucleation and growth; namely, much less primary graphite precipitates could be observed on the metallographic section when compared to the four other alloys.

In most cases, the graphite lamellae observed in the reference alloy have smooth edges and a more or less constant thickness that may be indicative of a monotonous growth. Bulk graphite appears smooth as illustrated in Figure 4 where an example of an SEM image is associated with SIMS maps of $\mathrm{C}, \mathrm{Fe}, \mathrm{Si}, \mathrm{Mg}$, and $\mathrm{Cu}$. The observed graphite did not contain significant amounts of $\mathrm{Fe}$ and $\mathrm{Cu}$, but little $\mathrm{Si}$ and a very homogeneous distribution of $\mathrm{Mg}$. It was seen that this latter element appeared as well in enriched spots containing also Mn (not shown in the figure) but outside the graphite lamellae. These are certainly oxide particles similar to those mentioned in other previous studies [10, 19]. 


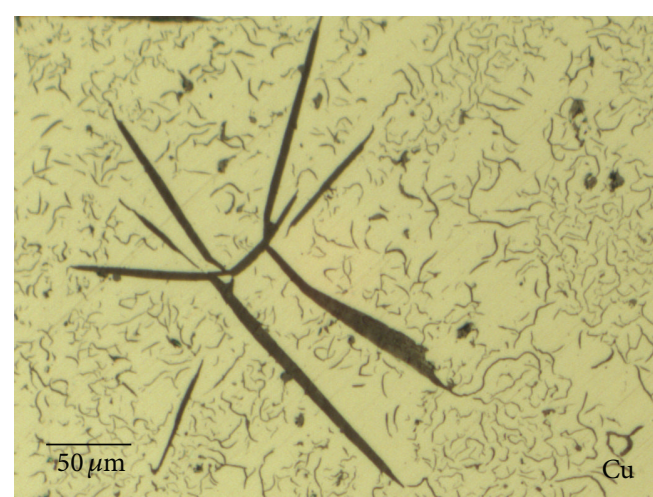

(a)

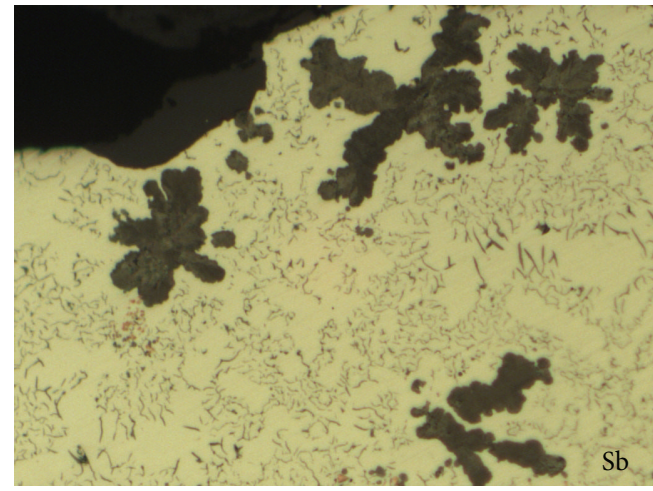

(c)

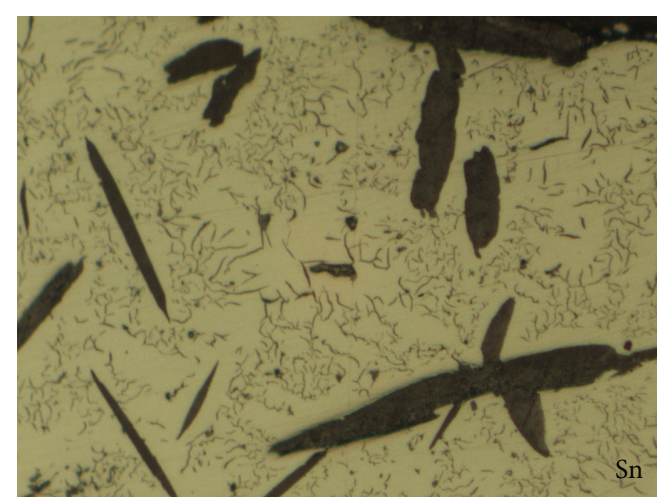

(b)

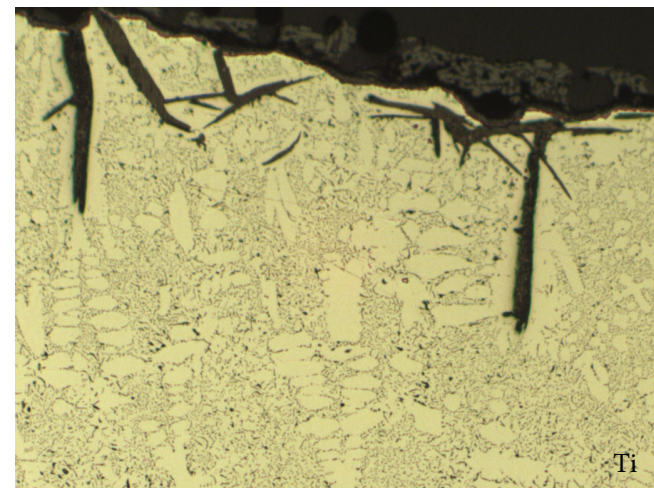

(d)

FIgURE 3: Optical micrographs of the upper sample surface of all four alloys with specific additions. The scale is the same for all micrographs.
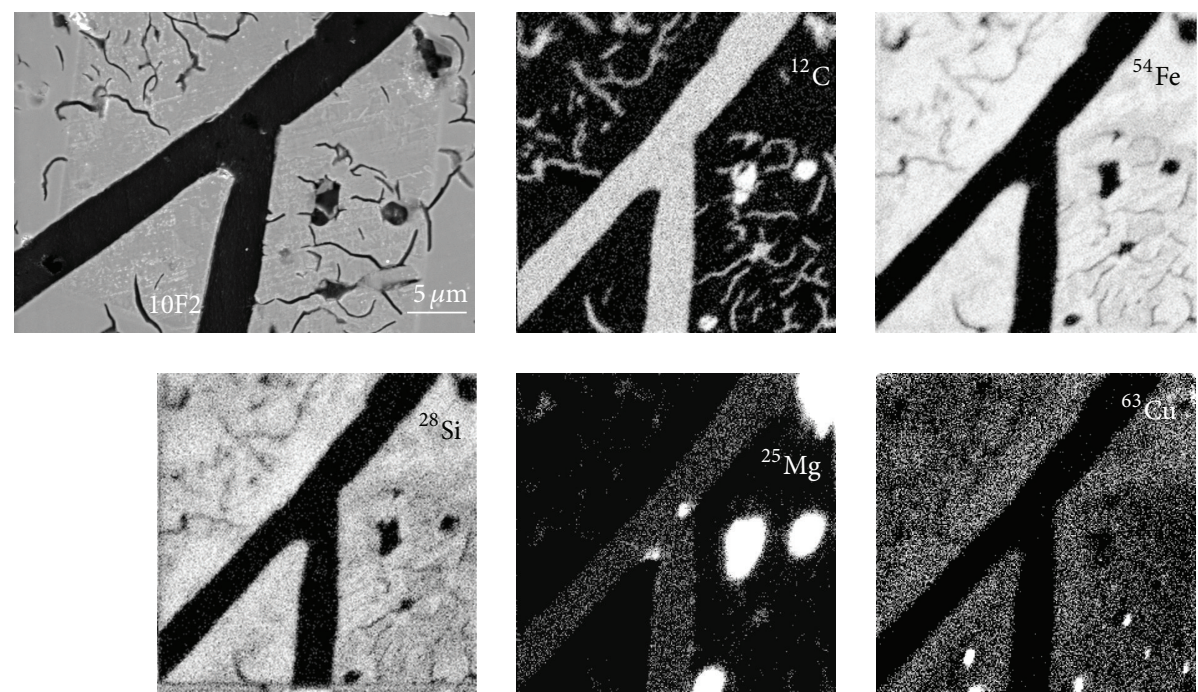

FIGURE 4: SEM micrograph of a graphite precipitate in the reference 10F2 alloy and SIMS maps (logarithmic scale) of C, Fe, Si, Mg, and Cu.

Sometimes, branched lamellae presenting a perturbed bulk graphite structure could also be seen in the reference alloy as illustrated in Figure 5. The SEM micrograph shows bulk graphite to present an irregular surface on the section while SIMS maps of Si and Fe display irregular distribution of these elements. Mn showed an inhomogeneous distribution as $\mathrm{Si}$ and $\mathrm{Fe}$ while $\mathrm{Mg}$ remained homogeneous (maps not shown in the figure). It is worth stressing that the enriched areas in $\mathrm{Si}$ and $\mathrm{Fe}$ in the bulk graphite are more or less aligned in a layered structure parallel to the long axis of the lamellae.

Figure 6 shows a typical example of a graphite lamella for each of the four alloys with specific additions together with SIMS maps of C and Si. Carbon maps are shown as they make clearer the shape of the graphite precipitates that are 

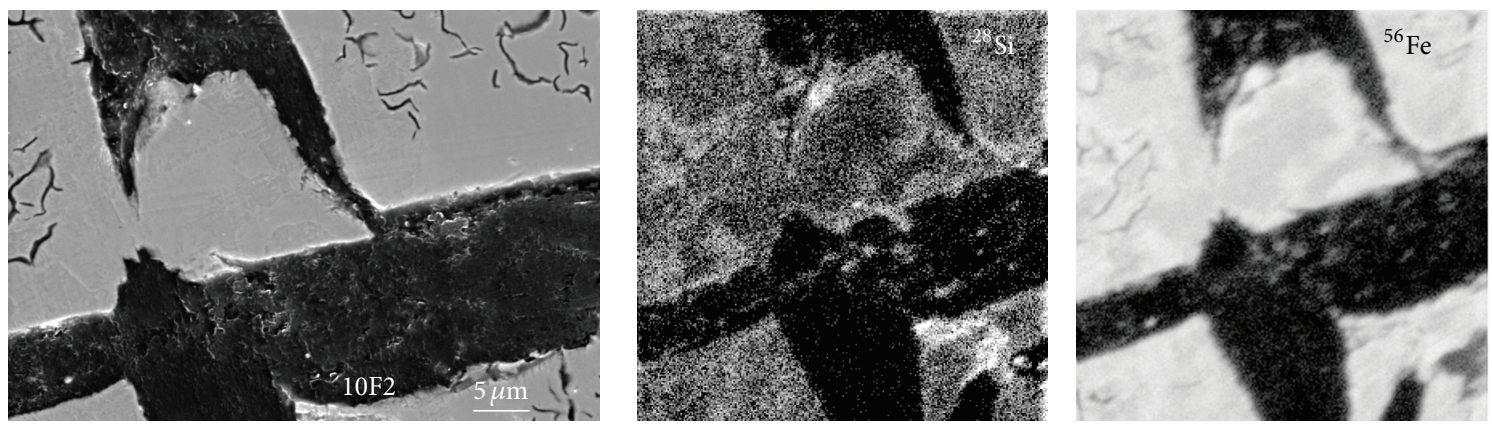

FIGURE 5: SEM micrograph of a perturbed graphite junction and related Fe and Si SIMS maps (logarithmic scale) in the reference 10F2 alloy.
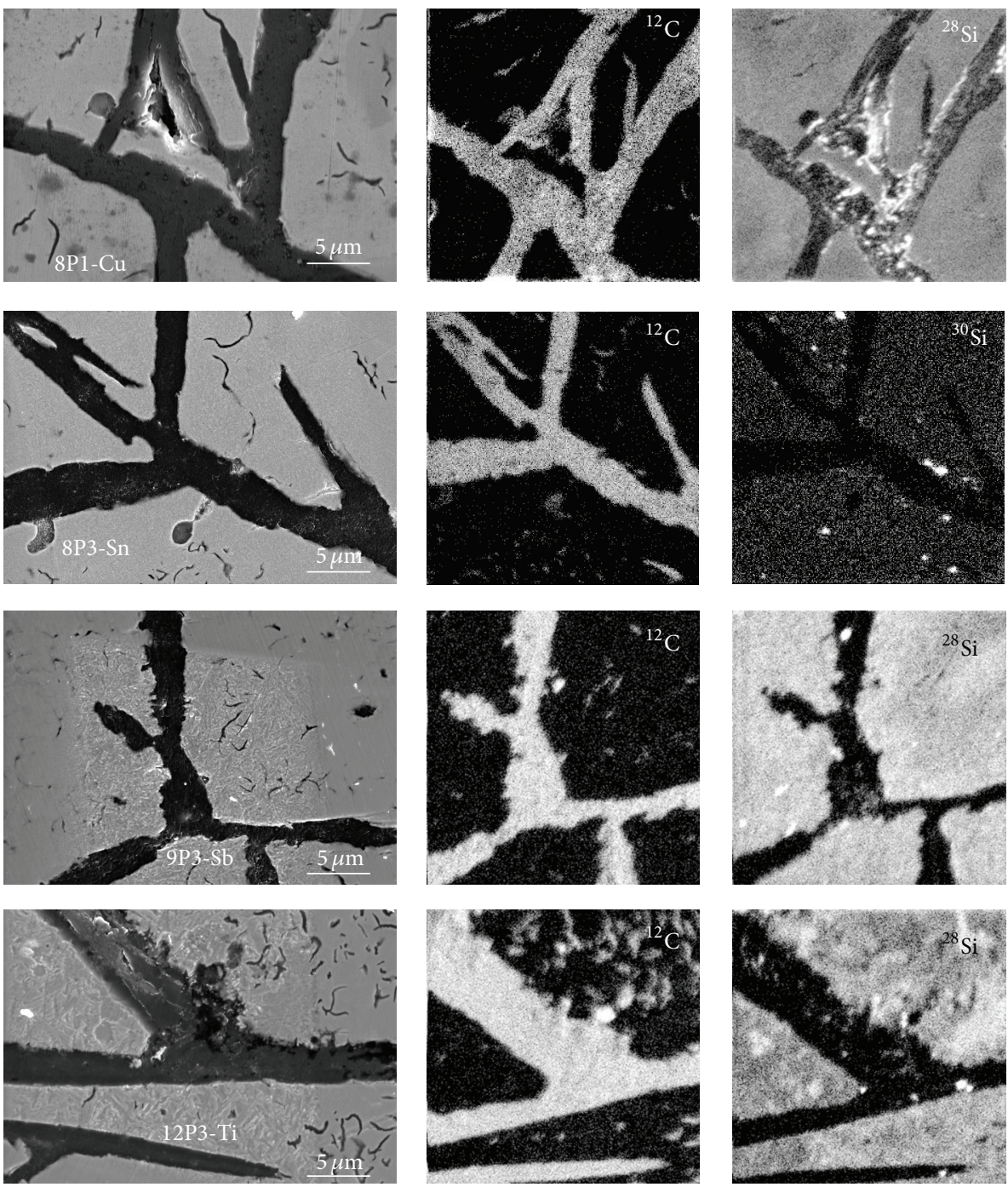

FIGURE 6: SEM micrograph and SIMS maps (logarithmic scale) of C and Si of a graphite precipitate in each of the alloys with specific additions.

seen to be perturbed on the SEM micrographs in Figure 6 whereas the bulk graphite appeared smooth in Figure 4. Silicon showed an inhomogeneous distribution, and this was also the case of iron and manganese (not shown in the figure). There are some spots in the silicon maps, most often outside the graphite lamellae, that are certainly oxides. Further, it appeared evident that the graphite/matrix interface is much more irregular in these alloys than it was in the reference one. This irregularity increases from $\mathrm{Cu}$ to $\mathrm{Sn}$ and from $\mathrm{Sn}$ to $\mathrm{Sb}$ as already pointed out in relation to Figure 3. Graphite precipitates in the Ti-bearing alloy present a less perturbed surface than in the case of alloys with $\mathrm{Sn}$ or Sb additions, 

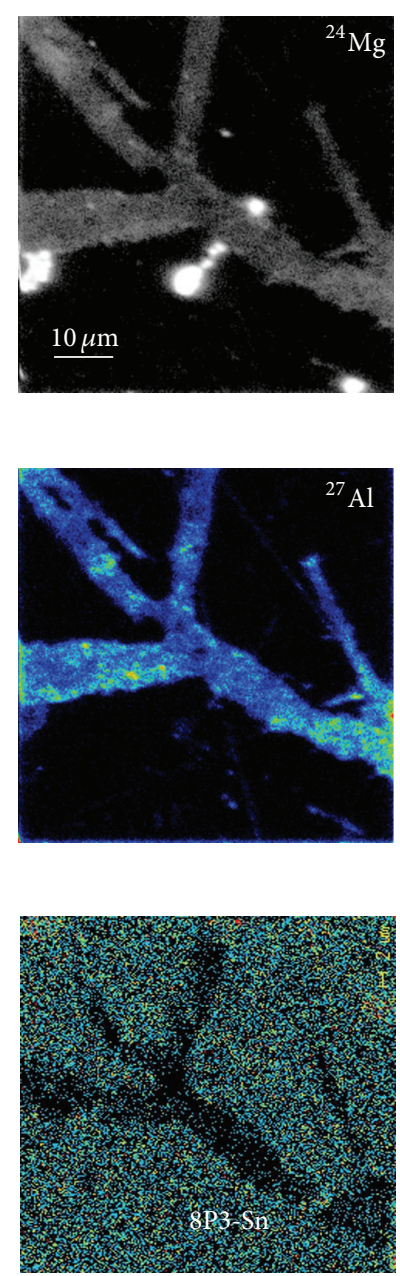

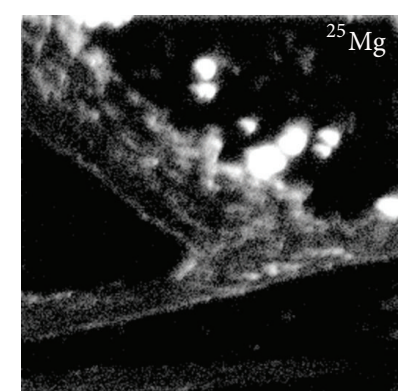

(a)
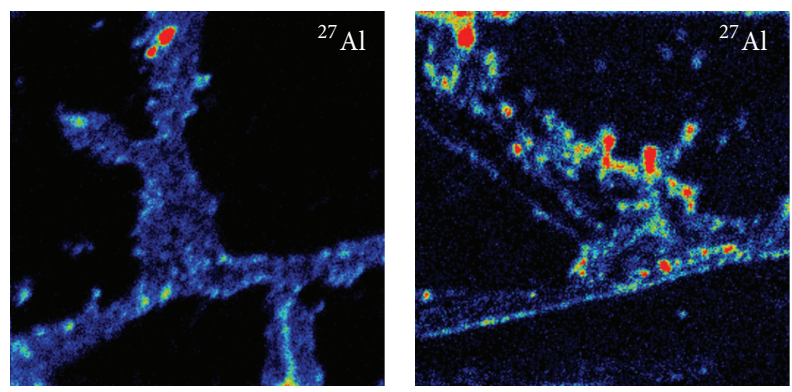

(b)
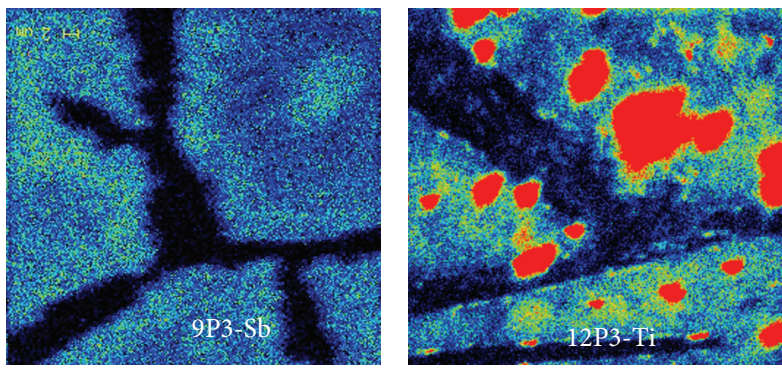

(c)

FIGURE 7: SIMS maps of $\mathrm{Mg}$ (upper row), $\mathrm{Al}$ (middle row) and, respectively, Sn, Sb, and Ti (lower row) for the Sn-, Sb-, and Ti-bearing alloys. For clarity, linear scale images were selected for $\mathrm{Al}, \mathrm{Sn}$, and $\mathrm{Sb}$ maps and logarithmic scale images for the others. The scale is the same for all images.

but they contain metallic elements as is the case for the other alloys.

Although $\mathrm{Mg}$ has decreased during remelting at a level where it cannot act anymore as a spheroidizer, it has been observed that some traces of this element are detected in graphite precipitates in the reference alloy. This was also the case for the alloys with specific additions as seen with the maps in the upper row of Figure 7 for the Sn-, Sb-, and Tibearing alloys. Similarly, aluminum that is added at a very low level through inoculation is anyway easily detected by SIMS as illustrated in Figure 7, second row. Both $\mathrm{Mg}$ and $\mathrm{Al}$ appear nonhomogeneously distributed within graphite, generally at a low level but sometimes also as spots though most of these latter are located outside the precipitates. A layered structure of the enriched areas as in Figure 5 may be guessed in the images of the Ti-bearing alloy.

In the bottom row of Figure 7, a map of $\mathrm{Sn}, \mathrm{Sb}$, and $\mathrm{Ti}$ is also shown for the $\mathrm{Sn}-, \mathrm{Sb}-$, and $\mathrm{Ti}$-bearing alloys, respectively. It is seen that $\mathrm{Sn}$ and $\mathrm{Sb}$ appear at very low level in graphite with respect to the matrix and that no built-up of these elements could be detected at the graphite matrix interface. $\mathrm{Ti}$ as well is present at a low level in graphite with a heterogeneous distribution but appears mainly as spots of presumably oxide particles outside graphite. Similarly, although not shown, no build-up of copper could be found in any of the mappings of this element.

In order to exemplify the lack of spike at the interface between primary graphite and matrix, line scans were drawn from the SIMS images. Figure 8 compares such scans for the reference and the Sb-bearing alloys. The variations along the profiles outside the lamellae are essentially due to the fine eutectic developed during rapid cooling. At the micron scale, that is, the resolution of the SIMS probe in the present conditions, no spike in any of the alloying or trace elements could be observed at the outer surface of primary graphite precipitates. The most important information obtained from these graphs is that the variations in low-level elements $(\mathrm{Mg}$, $\mathrm{Cu}$, and $\mathrm{Si}$ ) within graphite are much more pronounced in the alloy with specific additions than in the reference one. 


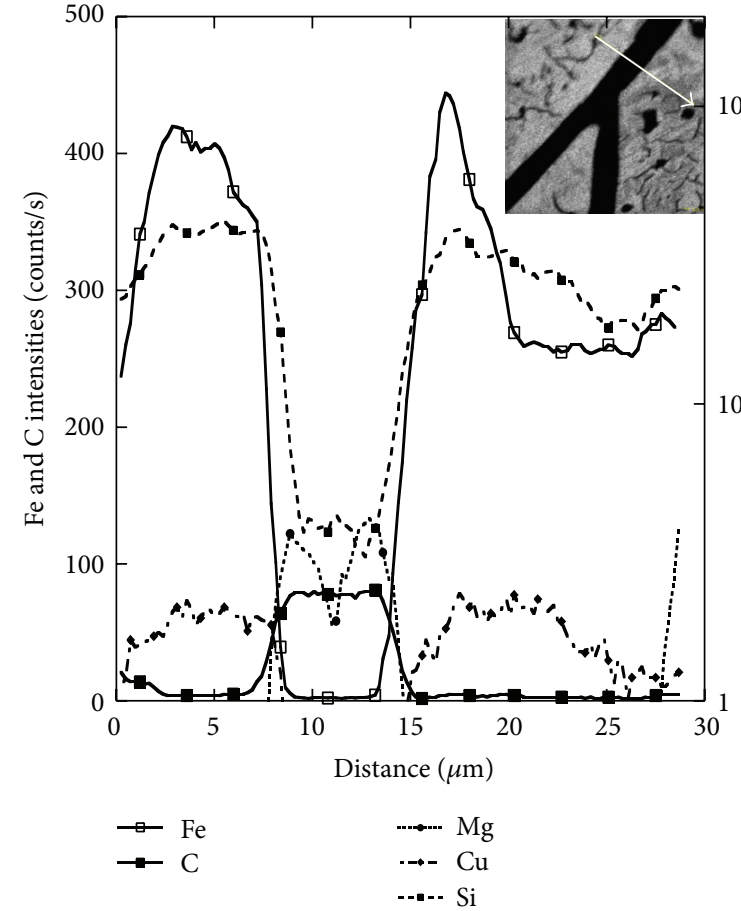

(a)

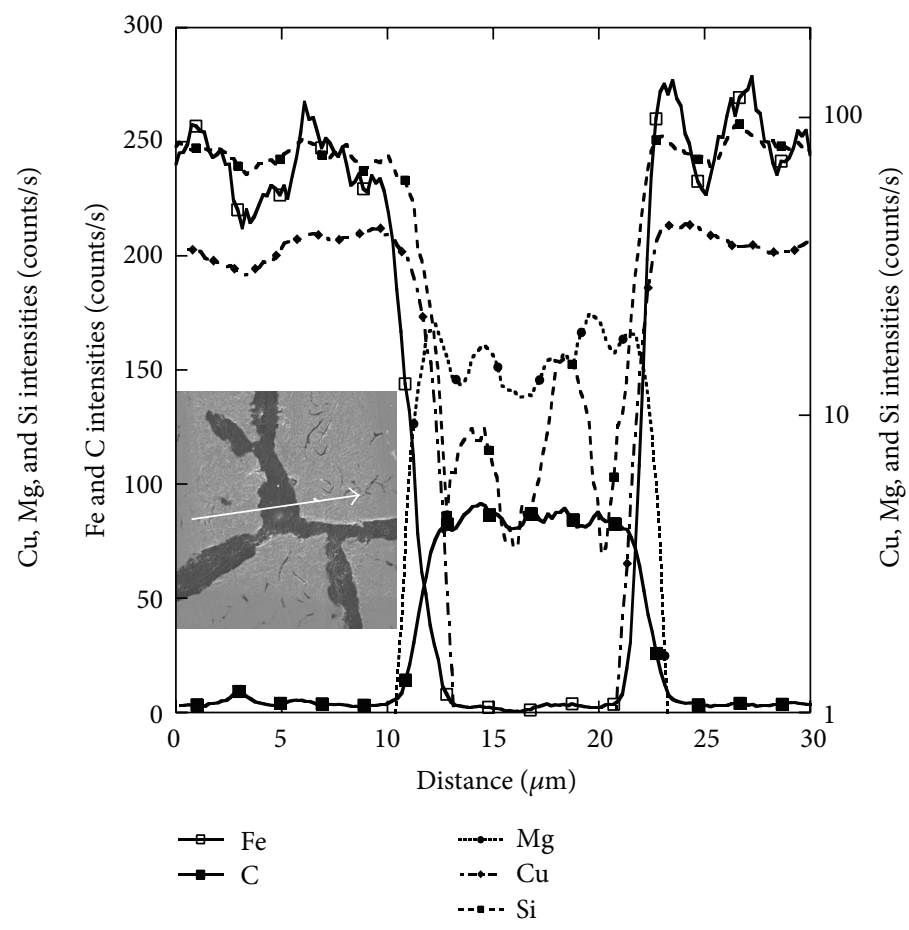

(b)

FIGURE 8: Evolution of SIMS intensities through graphite along the arrow indicated on the SEM image for the reference alloy (a) and the Sb-bearing one (b).

Finally, SIMS measurements in the iron-rich matrix have been made quantitative for some elements following the procedure described in Section 2. Though this procedure does not apply to graphite which may have a response to ion bombardment different to that of the iron-rich matrix, the values obtained have been used for comparison with the literature data. When the concentration of an element was not homogeneous inside graphite, the maximal concentration was selected. Table 2 lists the average amount of the elements that could be measured in graphite, as well as corresponding values reported by Fidos [7] from SIMS results and Francis [4] from chemical analyses. $\mathrm{Al}$ and $\mathrm{Mg}$ that are residuals of spheroidization and inoculation treatments enter in graphite at very low levels, generally much lower than those reported by Fidos and Francis. Si is present in graphite at a level of a few tenths of per cent, while Mn varies from one sample to another from traces to low level at $0.12 \mathrm{wt} . \%$. The contents in these latter elements are within the range reported by Fidos and Francis. When copper was not added to the alloy (10F2), it is found at a very low level as also observed by Francis. For the other alloys in which $\mathrm{Cu}$ was added at a level of $1 \mathrm{wt} . \%$, it is seen that this element enters graphite in varying amounts, from 100 to several hundreds of ppm. The other elements studied in this work enter in graphite as traces at a level lower than 100 ppm for Sn and Ti and lower than 10 ppm for Sb.

\section{Discussion}

The results presented above show that at least some elements affecting spheroidal growth are also effective in altering
TABLE 2: Concentrations of trace elements in graphite for the five alloys studied (wt.\%) and data from the literature for SG or LG cast iron $[4,7]$.

\begin{tabular}{lcccccc}
\hline & $\mathrm{Al}$ & $\mathrm{Si}$ & $\mathrm{Mn}$ & $\mathrm{Cu}$ & $\mathrm{Mg}$ & Others \\
\hline 10F2 & n.d. & 0.658 & 0.007 & 0.001 & 0.001 & \\
8P1-Cu & 0.012 & 0.13 & 0.039 & 0.060 & 0.0001 & \\
8P3-Sn & 0.024 & 1.94 & 0.119 & 0.086 & n.d. & $0.008 \mathrm{Sn}$ \\
9P3-Sb & 0.061 & 0.69 & 0.086 & 0.013 & 0.004 & $0.0009 \mathrm{Sb}$ \\
12P3-Ti & 0.0003 & 0.464 & 0.004 & 0.008 & 0.012 & $0.003 \mathrm{Ti}$ \\
[7] SG & $0.015-0.8$ & $0.12-3.0$ & $0.01-0.15$ & & $0.17-0.19$ & \\
[7] LG & $0.4-4.0$ & $0.5-7.3$ & $0.1-0.5$ & & $0.03-0.17$ & \\
[4] SG & 0.025 & 0.50 & 0.001 & 0.001 & 0.03 & $0.003 \mathrm{Ti}$ \\
[4] LG & 0.01 & 0.015 & 0.002 & 0.003 & 0.008 & \\
\hline
\end{tabular}

n.d.: not determined.

lamellar growth. The possible mechanisms are discussed below considering successively the three following items: (i) presence of foreign atoms in graphite; (ii) redistribution of foreign atoms at the outer surface of graphite; and (iii) intercalation and spot alignment.

4.1. Presence of Foreign Atoms in Graphite. As mentioned in the introduction, the review performed by Lux [1] in the early 70 s showed that the presence of foreign elements within graphite in cast irons has been reported since long. This was most often evidenced by chemical analysis of extracted graphite particles and of the ash obtained from them, for example, by Francis [4]. Use of other methods such as 
autoradiography to locate elements within graphite as done by Hillert and Lindblom [20] proved not to be evident as discussed by Olette et al. [21] because of the penetration distance of the ray emitted by the isotopes. Using the more sensitive and accurate SIMS technique, Franklin and Stark $[9,10]$ and Fidos $[7,8]$ showed that even and smooth distribution of foreign elements may be observed within graphite precipitates. By simulation, Fidos $[7,8]$ could render his SIMS analyses semiquantitative. He then showed that the total amount of foreign species can go up to about $8.2 \mathrm{wt} . \%$ at the edge of graphite particles when it is only $0.2 \mathrm{wt} . \%$ in the interior $[7,8]$. Also, foreign elements in bulk SG graphite often appear as spots, for example, Fe-rich particles observed by metallography when large enough [1] or by Auger mapping [19] and Ti-rich, Ca-rich, and Mg-rich particles that could be oxides observed by SIMS [10].

The present results do confirm that many elements enter into graphite, either homogeneously or heterogeneously distributed or else tight in enriched particles. It has been observed that in the absence of any of the elements considered in the present investigation $(\mathrm{Cu}, \mathrm{Ti}, \mathrm{Sn}$, and $\mathrm{Sb})$, the distribution of metallic elements in graphite of the reference alloy appears in general even. In turn, it was observed that in alloys with specific additions, foreign elements were most generally distributed unevenly and associated with perturbed appearance of bulk graphite in SEM and wavy graphite/ matrix interfaces. This conclusion may be in close relationship with the trend that, at given cooling conditions, increasing alloy purity leads graphite to grow as very regularly shaped plates rather than as curved lamellae as reported by Ruth and Turpin [22]. In the present work, it was found that the effect of added species increases as $\mathrm{Cu}, \mathrm{Ti}, \mathrm{Sn}$, and $\mathrm{Sb}$.

4.2. Redistribution of Elements at Graphite Interface. A striking feature of the present results is that none of the added elements considered in this work could be detected within graphite at high level and no enrichment could be noted at the outer graphite surface. From the works he reviewed, Lux [1] concluded that the absence of any enrichment in nodularizing elements in the vicinity of the nodule-metal interface provided a clear evidence for the direct formation of nodules from the melt. Using AES experiments, Qin and Zu [23] arrived to the same conclusion as Lux [1] and considered that elements rejected from graphite when growing separately are rapidly redistributed within the whole melt by diffusion. This appears to be the case as well in the present work and, accordingly, the observed shape changes are not related to any significant solute piling-up at the graphite-melt interface. Following Francis [4] it may be inferred that solute pileup at the graphite outer surface as sometimes reported [2426] results either from two-phase eutectic growth or from graphite growth in solid state at lower temperature as a process we suggest resembling grain boundary segregation.

4.3. Intercalation and Spot Alignment. Using SIMS on LG, Franklin and Stark [10] noticed oxygen to be uniformly distributed in graphite while the S signal showed a periodicity that they associated with the substructure of graphite flakes. Such a substructure that consists of laths stacked on each other has been detailed since long for both SG and LG [27]. From their results, Franklin and Stark [10] concluded that it is $\mathrm{O}$ rather than $\mathrm{S}$ that adsorbs on the prism plane while $\mathrm{S}$ segregates at the interface between laths. Using TEM results, intercalation between laths of other foreign species such as Ce has been suggested by Purdy and Audier for LG and SG [28] and by Miao et al. for SG [29]. These latter authors proposed that intercalation layers are associated with the occurrence of crystalline faults within graphite. In the present work, intercalation at the scale of a few atoms width could not be investigated but instead alignment of particles could be observed in some cases that are guessed to relate to lath stacking. Moreover, it has been noticed that addition of the studied specific elements affects the stacking appearanceapparent quality-of graphite laths with the bulk graphite appearing less compact than in the reference alloy. It may be claimed that the added elements do enter graphite by intercalating between laths. This could lead to a more faulted stacking of laths accounting for the more foliated aspect of the graphite precipitates. Such a correlation is certainly worth of further investigation.

\section{Conclusion}

As reported since long, graphite in cast irons contains small but definite amounts of several elements. While their distribution seems homogeneous in general for the reference alloy investigated, it was found to be inhomogeneous in the grades containing $\mathrm{Cu}$ and with additions of $\mathrm{Sn}, \mathrm{Sb}$, and $\mathrm{Ti}$. Further, it was observed that the graphite precipitates in the alloys with specific additions present a disturbed aspect in the bulk and a wavy interface with the matrix. These latter observations were most marked with addition of $\mathrm{Sb}$ which gives rounded precipitates together with lamellas and with Sn that significantly increases the average width of the lamellae. SIMS mapping did not evidence any build-up of added elements around graphite precipitates, and this observation suggests that additives and trace elements affect graphite growth at an atomic level, for example, by perturbing its crystalline structure.

\section{References}

[1] B. Lux, "On the theory of nodular graphite formation in cast iron-part I: experimental observations of nodular graphite formation during the solidification of cast iron melts," Giessereiforschung in English, vol. 22, pp. 65-81, 1970.

[2] H. D. Merchant, "Solidification of cast iron-a review of literature," in Proc. Recent Research on Cast Iron, H. H. Merchant, Ed., pp. 1-100, ASM, New York, NY, USA, 1964.

[3] A. Javaid and C. R. Loper, "Production of heavy-section ductile cast irons," AFS Transactions, vol. 103, pp. 135-150, 1995.

[4] B. Francis, "Heterogeneous nuclei and graphite chemistry in flake and nodular cast irons," Metallurgical Transactions A, vol. 10, no. 1, pp. 21-31, 1979.

[5] S. Feng, M. Ren, M. Zhong et al., "Analysis of the distribution of trace elements in nodular cast iron by SPM," Nuclear Instruments and Methods in Physics Research B, vol. 104, no. 1-4, pp. 557-560, 1995. 
[6] S. L. Feng, M. Q. Ren, and M. Zhong, "PIXE analysis of antinodularizing elements $\mathrm{Al}, \mathrm{Pb}$ and $\mathrm{Bi}$ in nodular cast iron," $\mathrm{Nu}$ clear Instruments and Methods in Physics Research B, vol. 109110, pp. 584-586, 1996.

[7] H. Fidos, "A study of the graphite morphology in nodular cast iron," FWP Journal, vol. 17, no. 10, pp. 9-54, 1977.

[8] H. Fidos, "Structural analysis of a graphite nodule and surrounding halo in ductile iron," FWP Journal, vol. 22, no. 9, pp. $11-62,1982$.

[9] S. E. Franklin and R. A. Stark, "Application of secondary ion mass spectrometry to study of graphite morphology in cast iron," Metal Science, vol. 18, no. 4, pp. 187-200, 1984.

[10] S. E. Franklin and R. A. Stark, "Further use of secondary ion mass spectrometry in the study of graphite morphology control in cast irons," in The Physical Metallurgy of Cast Iron, Mat. Res. Soc. Symp. Proc, H. Fredriksson and M. Hillert, Eds., vol. 34, pp. 25-35, Norh-Holland, New York, NY, USA, 1985.

[11] W. Patterson, H. Geilenberg, and B. Lange, "Anwachsversuche an Graphit-Impfkristallen aus kohlenstoffgesattigten Eisenschmelzen," Giesserei-Forschung, vol. 26, p. 1218, 1974.

[12] H. Geilenberg and B. Lange, "Growth experiments with graphite seed crystals from iron melts saturated in carbon," in The Metallurgy of Cast Iron, B. Lux, I. Minkoff, and F. Mollard, Eds., pp. 529-543, Georgi Publishing company, St Saphorin, Switzerland, 1975.

[13] I. Asenjo, J. Lacaze, P. Larrañaga, S. Méndez, J. Sertucha, and R. Suárez, "Microstructure investigation of small-section nodular iron castings with chunky graphite," Key Engineering Materials, vol. 457, pp. 52-57, 2011.

[14] N. Valle, K. Theuwissen, J. Sertucha, and J. Lacaze, "Effect of various dopant elements on primary graphite growth," IOP Conference Series: Materials Science and Engineering, vol. 27, Article ID 012026, 2012.

[15] J. Serrallach, J. Lacaze, J. Sertucha, R. Suárez, and A. Monzón, "Effect of selected alloying elements on mechanical properties of pearlitic nodular cast irons," Key Engineering Materials, vol. 457, pp. 361-366, 2011.

[16] J. M. Chabala, R. Levi-Setti, and Y. L. Wang, "Practical resolution limits of imaging microanalysis with a scanning ion microprobe," Applied Surface Science, vol. 32, no. 1-2, pp. 10-32, 1988.

[17] G. Frache, B. E. Adib, J.-N. Audinot, and H.-N. Migeon, "Evaluation of ionization yields under gallium bombardment," Surface and Interface Analysis, vol. 43, no. 1-2, pp. 639-642, 2011.

[18] R. G. Wilson, F. A. Stevie, and C. W. Magee, Secondary Ion Mass Spectrometry, A Practical Handbook for Depth Profiling and Bulk Impurity Analysis, John Wiley \& Sons, New York, NY, USA, 1989.

[19] W. C. Johnson and H. B. Smartt, "The role of interphase boundary adsorption in the formation of spheroidal graphite in cast iron," Metallurgical Transactions A, vol. 8, no. 4, pp. 553-565, 1977.

[20] M. Hillert and Y. Lindbolm, "The growth of nodular graphite," The Journal of the Iron and Steel Institute, vol. 148, pp. 388-390, 1954.

[21] M. Olette, A. Kohn, and P. Kozakevitch, "Contribution à l'étude du mécanisme de formation du graphite primaire dans les fontes," Fonderie, vol. 229, pp. 87-99, 1965.

[22] J. C. Ruth and M. Turpin, "Structures de solidification unidirectionnelle des eutectiques fer-carbone," Mémoires Scientifiques Revue de Métallurgie, vol. 66, pp. 633-640, 1969.
[23] Z. Qin and Z. Zu, "Dynamic segregation of sulphur in cast iron," Acta Metallurgica Sinica, vol. 2, pp. 202-204, 1989.

[24] W. C. Johnson and B. V. Kovacs, "The effect of additives on the eutectoid transformation of ductile iron," Metallurgical Transactions A, vol. 9, no. 2, pp. 219-229, 1978.

[25] B. V. Kovacs, "Pearlite stabilization in cast irons," AFS Transactions, vol. 89, pp. 79-96, 1980.

[26] B. C. Liu, T. X. Li, Z. J. Rue, X. Y. Yang, E. Q. Huo, and C. R. Loper, "The role of antimony inn heavy-section ductile iron," AFS Transactions, vol. 98, pp. 753-757, 1990.

[27] M. J. Hunter and G. A. Chadwick, "Structure of spheroidal graphite," The Journal of the Iron and Steel Institute, vol. 210, pp. 117-123, 1972.

[28] G. R. Purdy and M. Audier, "Electron microscopical observations of graphite in cast irons," in The Physical Metallurgy of Cast Iron, Mat. Res. Soc. Symp. Proc, H. Fredriksson and M. Hillert, Eds., vol. 34, pp. 13-23, Norh-Holland, New York, NY, USA, 1985.

[29] B. Miao, K. Fang, W. Bian, and G. Liu, "On the microstructure of graphite spherulites in cast irons by TEM and HREM," Acta Metallurgica et Materialia, vol. 38, no. 11, pp. 2167-2174, 1990. 

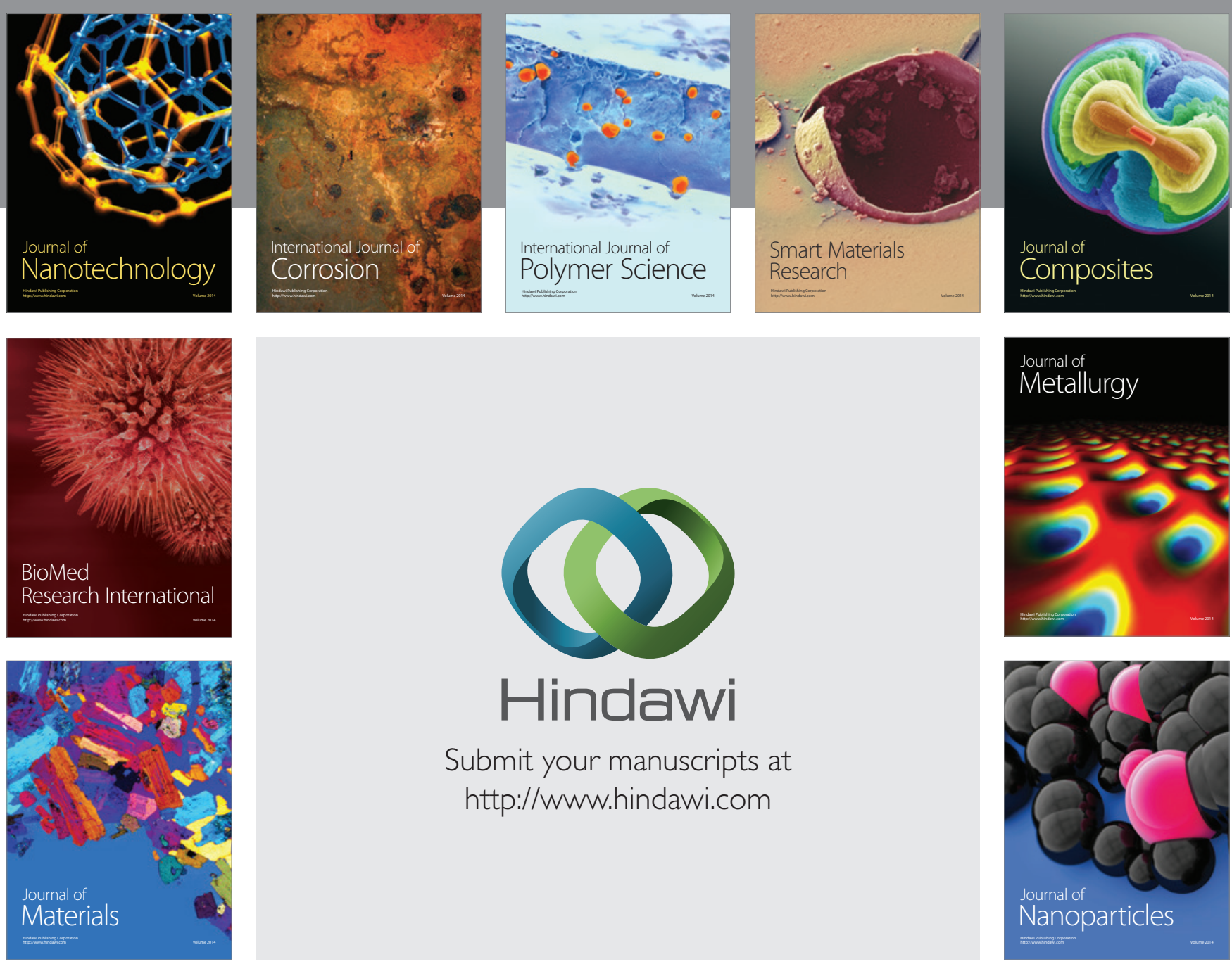

Submit your manuscripts at http://www.hindawi.com
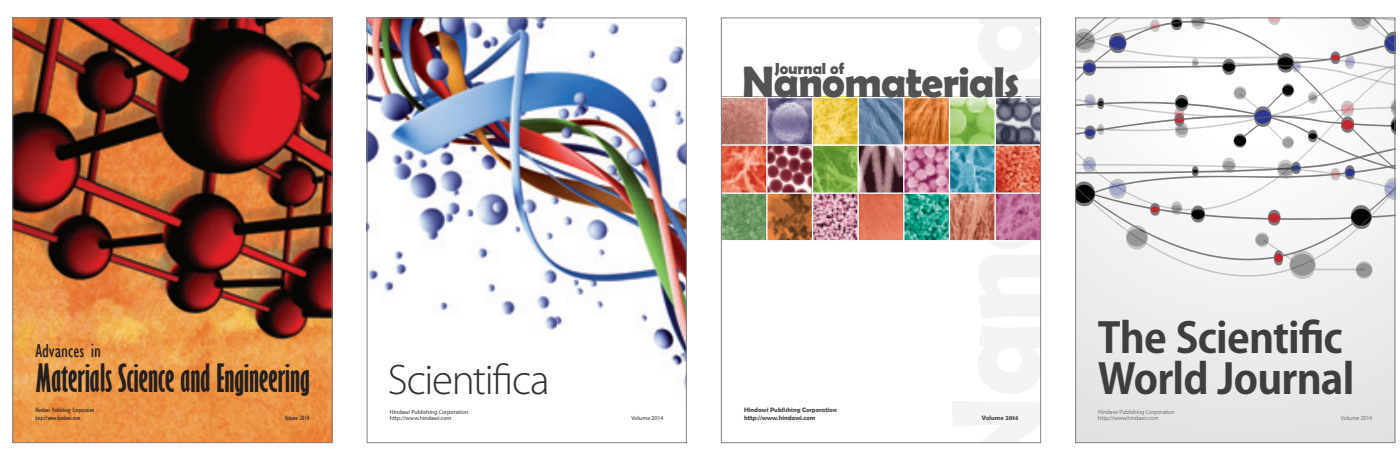

\section{The Scientific World Journal}
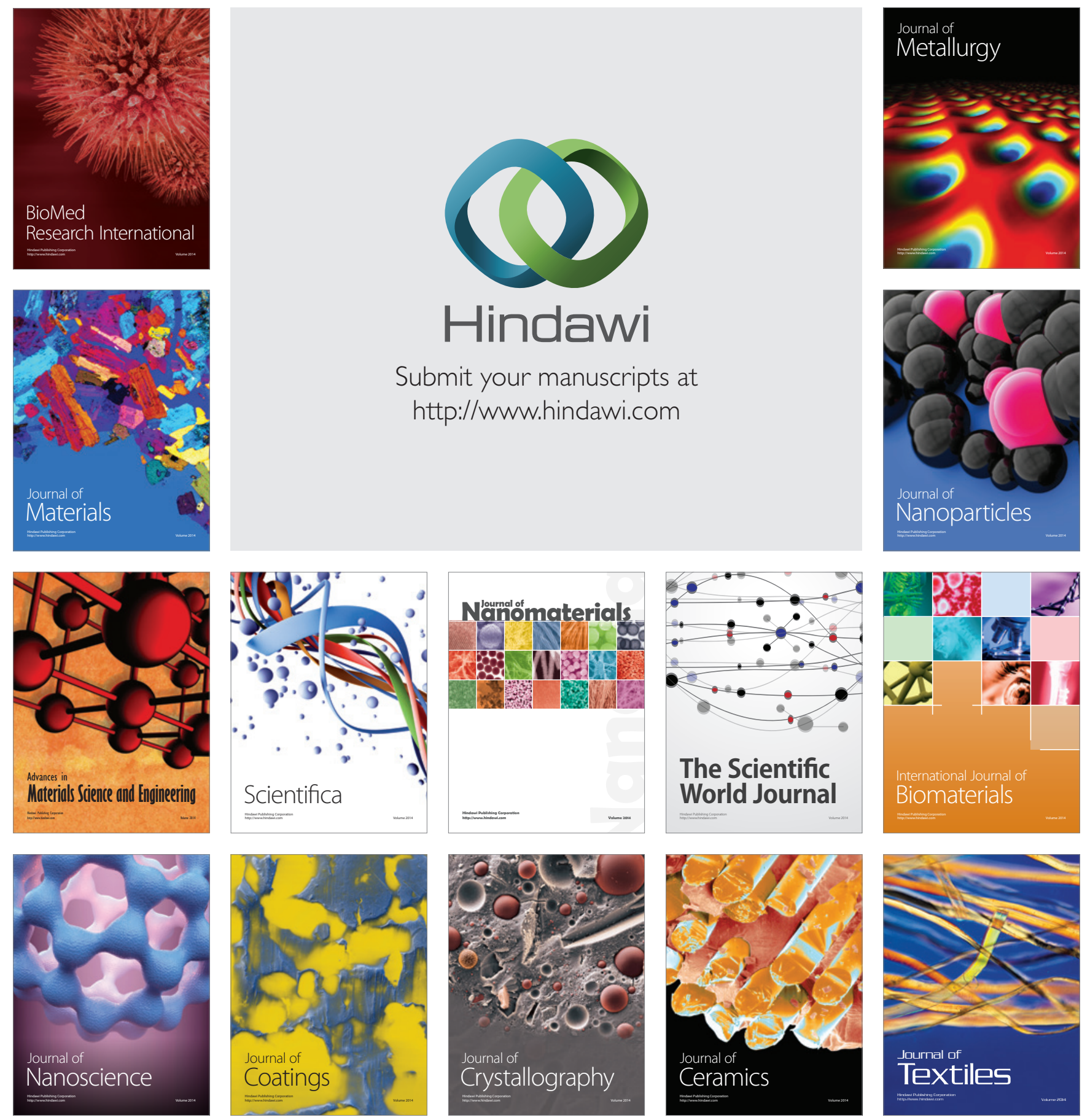